\title{
Embalses, miedo y salud humana: a propósito de la emergencia en Hidroituango
}

\section{Dams, fear and human health: purposely the emergency in Hidroituango}

\author{
Alvaro-J Idrovo
}

Forma de citar: Idrovo, AJ. Embalses, miedo y salud humana: a propósito de la emergencia en Hidoituango. Rev Univ Ind Santander Salud. 50(3): 193-194. doi: http://dx.doi.org/10.18273/revsal.v50n3-2018004 (c) (1)

Desde Abril de 2018, la represa de Hidroituango está en estado de alerta o emergencia debido a varios derrumbes de tierra que complicaron el proceso de construcción, aumentando el riesgo de que se rompa la estructura, lo que podría llevar a un desastre masivo de daños incalculables río abajo por las inundaciones que ocasionaría. Si bien, la ruptura de embalses no es un hecho frecuente, sí han ocurrido muchos con desenlaces catastróficos ${ }^{1}$. Algunos de los que más vidas humanas han afectado son los ocurridos en las represas de Banqiao y Shimantan (Zhumadian, China) en 1975 con 171.000 muertos; Machchu-2 (Morbi, India) en 1979 con 5.000 muertos; South Fork (Johnstown, Pennsylvania, Estados Unidos) en 1889 con 2.209 muertos; Sempor (Java Central, Indonesia) en 1967 con 2.000 muertos; Möhne (Ruhr, Alemania) en 1943 con 1.579 muertos; Kurenivka (Kiev, Ucrania) en 1961 con 1.500 muertos, Tigra (Gwalior, India) en 1917 con 1.000 muertos, y Panshet (Pune, India) en 1961 con 1.000 muertos. A estos casos hay que sumar las decenas de rupturas de embalses con menos muertes, pero con grandes desastres ambientales ${ }^{2}$.

Ante una situación como esta es normal que la población sienta miedo, pese a que los ingenieros constructores y los expertos en desastres suelan percibir menor riesgo ${ }^{3}$. El miedo es un estado motivacional provocado por estímulos específicos que pueden dar origen a una conducta defensiva o de escape ${ }^{4}$, siendo en este caso de interés el estímulo un desastre antropogénico ${ }^{5}$. En ese sentido, el miedo debe entenderse como un factor de protección que puede expandirse entre los miembros de una población de manera similar a una enfermedad infecciosa ${ }^{6}$.

El miedo constante genera respuestas neuroendocrinas, que pueden facilitar problemas de salud ${ }^{7,8}$. El más conocido de todos es el desorden de estrés postraumático, el cual suele ser más frecuente entre individuos susceptibles, como quienes han sido víctimas de abuso infantil ${ }^{9}$. Sin embargo, esa es apenas la punta del iceberg, y las problemáticas de salud mental con menor severidad son de una mayor ocurrencia, aunque no siempre con connotaciones de enfermedad. Hasta donde se ha informado a la opinión pública, los trabajadores de Hidroituango han tenido atención psicológica y se han incrementado las consultas de estrés, ansiedad, cefalea e hipertensión arterial entre la población civil. Por todas estas situaciones, el personal sanitario debe estar preparado adecuadamente a atender los afectados de este tipo de situaciones, que se están volviendo cada vez más frecuentes en el país.

\section{Referencias}

1. Lave LB, Balvanyos T. Risk analysis and management of dam safety. Risk Anal. 1998;18(4): 455-462. doi: https://doi.org/10.1111/j.1539-6924.1998.tb00360.x.

2. U.S. Department of the Interior Bureau of Reclamation. RCEM - Reclamation Consequence Estimating Methodology. Dam failure and flood event case history compilation. U.S. Department of the Interior Bureau of Reclamation; 2014.

1. Universidad Industrial de Santander. Bucaramanga, Colombia.

Correspondencia: Alvaro Javier Idrovo. Dirección: Carrera 32 No. 29-31, Escuela de Salud Pública. Telefono: +577 6344000 ext.3123. Correo electrónico: idrovoaj@uis.edu.co 
3. Green $\mathrm{CH}$, Tunstall SM, Fordham MH. The risks from flooding: which risks and whose perception? Disasters. 1991; 15(3): 227-236. doi: https://doi.org/10.1111/j.1467-7717.1991.tb00456.x.

4. Steimer T. The biology of fear and anxiety-related behaviors. Dialogues Clin Neurosci. 2002; 4(3): 231-249.

5. Espinola M, Shultz JM, Espinel Z, Althouse BM, Cooper JL, Baingana F, et al. Fear-related behaviors in situations of mass threat. Disaster Health. 2016; 3(4): 102-111. doi: 10.1080/21665044.2016.1263141.

6. Hatfield E, Cacioppo J, Rapson RL. Emotional contagion. New York: Cambridge University Press; 1994.

7. Herry C, Johansen JP. Encoding of fear learning and memory in distributed neuronal circuits. Nat Neurosci. 2014; 17(12): 1644-1654. doi: 10.1038/nn.3869.

8. de Kloet ER, Joëls M, Holsboer F. Stress and the brain: from adaptation to disease. Nat Rev Neurosci. 2005; 6(6): 463-475.

9. Gonzalez P, Martinez KG. The role of stress and fear in the development of mental disorders. Psychiatr Clin North Am. 2014; 37(4): 535-546. doi: 10.1016/j.psc.2014.08.010. 